\title{
Eleições 2018 à luz da Folha de S. Paulo: a intersecção religiosa e neoliberal no discurso jornalístico
}

\author{
Aline $V_{a z}{ }^{1}$ \\ Marcela Barba Santos ${ }^{2}$ \\ Tarcis Prado Júnior ${ }^{3}$
}

\begin{abstract}
Resumo:
O estudo objetiva discutir como os tópicos religião e neoliberalismo se articulam no discurso jornalístico durante as eleições presidenciais de 2018. Como corpus desta pesquisa seleciona-se 69 notícias, que interseccionam menções religiosas e neoliberais, veiculadas no caderno especial "Eleições 2018" do jornal Folha de São Paulo. A partir de questões relacionadas às temáticas, religiosidades e candidatos em destaque, o estudo se desenvolve por meio de uma análise sistemática de conteúdo, incluindo a categorização e codificação das notícias. Logo, buscando perceber a confluência entre religião e neoliberalismo, durante a eleição corrente, conseguimos observar que o material jornalístico em estudo valorizou um discurso associado a moral e a segurança individual do sujeito, por vezes, apontando o cinismo e até mesmo as ditas fake news.
\end{abstract}

palavras-chave: Religião e política, neoliberalismo, eleições 2018.

\begin{abstract}
:
The aims of this essay is to verify how the topics religion and neoliberalism are articulated in the journalistic discourse, during the 2018 presidential elections. As a corpus of this research, 69 news items are selected, intersecting religious and neoliberal mentions, those published in the special section "Eleições 2018" in Folha de São Paulo newspaper. Based on points related to themes, religions and candidates, the study is developed through a systematic content analysis, including the categorization and codification of the news. Therefore, seeking to understand the confluence between religion and neoliberalism, during the current election, we observe that the journalistic material under study valued a discourse associated with the morality and individual's security, sometimes pointing out cynicism and even lies (the said fake news).
\end{abstract}

keywords: Religion and politics, neoliberalism, elections 2018.

\footnotetext{
1 Doutora e Mestre pelo Programa de Pós-Graduação em Comunicação e Linguagens da Universidade Tuiuti do Paraná. Pesquisadora no Grupo de Pesquisa Desdobramentos Simbólicos do Espaço Urbano em Narrativas Audiovisuais - GRUDES (PPGCom/UTP). alinevaz900@gmail.com

2 Mestranda pelo Programa de Pós-Graduação em Comunicação da Universidade Federal do Paraná (PPGCOM/UFPR); bolsista CAPES. Membro do Grupo de Pesquisa em Comunicação Política e Opinião Pública (CPOP-UFPR). barba.mbs@gmail.com 3 Doutor em Comunicação e Linguagens (Universidade Tuiuti do Paraná); Pós doutorando em Sociologia (Universidade Federal do Paraná); Mestre e Especialista em Saúde Pública (Universidade de São Paulo). tarcisjr@yahoo.com.br
} 


\section{VOZES $_{\text {\&DÁLORO }}^{\mid}$}

Itajaí, V. 20, n.01, jan-jun 2021

\section{Introdução}

A presença religiosa em processos políticos é tradicional na história do Brasil, considerando-se a atuação da Igreja Católica desde a colonização portuguesa até seu inicial apoio e sua posterior oposição à ditadura militar (ALENCAR, 2020, p. 171). Apesar do destaque católico em momentos políticos simbólicos, desde a última redemocratização há o surgimento de um novo protagonista religioso: os neopentecostais ${ }^{4}$. Esta vertente evangélica possui ampla visibilidade midiática e política, a exemplo dos canais televisivos e da Frente Parlamentar Evangélica que apresenta aumento sucessivo, próximo a uma tendência linear crescente a partir da década de 1990 (RODRIGUES-SILVEIRA; CERVI, 2019, p. 561).

Os neopentecostais se desenvolvem na política a partir de um discurso acentuadamente moralista. Segundo Ricardo Mariano (2011, p. 251), alinhados a defender a moral cristã, a família e os bons costumes, propõem integrar o Congresso Nacional no combate à descriminalização do aborto e do consumo de drogas, a união civil de homossexuais e a imoralidade. Pautas estas que dialogam com a vertente neoliberal referente ao conservadorismo dos costumes que, para Pierre Dardot e Christian Laval (2016), tende a exaltar valores ditos morais, por vezes, justificando-se ações conservadoras em prol do resgate (proteção e conservação) da família.

A valorização do dinheiro também é acrescida como elemento constituinte do bom cristão, especialmente o neopentecostal. A Teologia da Prosperidade afirma que "a posse, a aquisição e exibição de bens, a saúde em boas condições e a vida sem maiores problemas ou aflições são apresentados como provas da espiritualidade do fiel”. (MARIANO, 2014, p. 157). Logo, o insucesso financeiro do indivíduo retrata sua própria incapacidade, visto que seria reflexo da falta de fé e do não cumprimento das palavras escritas na Bíblia.

Essas novas subjetividades envolvem a percepção da mobilidade social como resultado do esforço individual e com a manifestação da graça de Deus nas próprias obras. A "teologia da prosperidade" postula uma afinidade entre a visão neoliberal e a prosperidade econômica, alheia ao reconhecimento da ação do Estado e das políticas públicas. Os programas televisivos destas igrejas fazem referência ao "Pacto com Deus" e ao progresso econômico que daí advém, alinhado ao

\footnotetext{
${ }^{4}$ Este segmento religioso é parte do pentecostalismo cristão, movimento evangélico que divide-se em três grupos: 1) o clássico, caracterizado pelo anticatolicismo, profundo sectarismo e ascetismo; 2) sem uma nomenclatura unânime, tem entre suas particularidades o início do evangelismo de cura divina, intenso uso de rádio e pregações itinerantes; 3) o neopentecostal, vertente que enfatiza a guerra espiritual contra o diabo, a Teologia da Prosperidade e caracteriza-se como o menos sectário e ascético de todos, assim como o que mais cresce e ocupa melhor espaço midiático (MARIANO, 2008).
} 


\section{VOZES $_{\text {\&IÁLOGO }}^{\mid}$}

Itajaí, V. 20, n.01, jan-jun 2021

empreendedorismo e a iniciativa individual. (GOLDSTEIN, 2020, p. 11-12, tradução nossa) ${ }^{5}$.

Note-se que no sistema neoliberal aquele que não aguenta a concorrência é visto como fraco, incompetente: “o discurso da 'realização de si mesmo' e do 'sucesso de vida' leva a uma estigmatização dos 'fracassados', dos 'perdidos' e dos infelizes, isto é, dos incapazes de aquiescer à norma social da felicidade" (DARDOT; LAVAL, 2016, p. 367).

Para Dardot e Laval (2016, p. 189), os anos 1980 são marcados no Ocidente pelo triunfo de políticas conservadoras e neoliberais - importante salientar ainda que o período demarcado foi também o da redemocratização e princípio do sucessivo protagonismo religioso neopentecostal no Brasil. Grosso modo, o neoliberalismo vem colocar em dúvida “[...] a propriedade pública das empresas, o sistema fiscal progressivo, a proteção social, o enquadramento do setor privado por regulamentações estritas, especialmente em matéria de direito trabalhista e representação dos assalariados”. Neste contexto, os indivíduos sofrem com o desamparo do Estado, sendo a igreja, por vezes, lugar que vem suprir a carência de políticas públicas (FILHO FIGUEREDO, 2005, p. 31), tornando-se algo paradoxal, pois à medida que a igreja se coloca como lugar de refúgio do cidadão excluído pelo Estado, exerce um certo poder público e, consequentemente, insere-se no ambiente político.

Logo, conforme observam Dardot e Laval (2016), o neoliberalismo, enquanto uma racionalização, expande-se além de uma ideologia ou de um tipo de política econômica, tratando-se de um sistema normativo, que estende a lógica do capital a todas as relações sociais (e esferas da vida). Ao passo que as políticas neoliberais do Estado deixam o sujeito desamparado, a igreja passa a ocupar um lugar de proteção social para o cidadão convertido em fiel, que logo encontra ali também um modo de vida neoliberal, pois este sistema transforma profundamente o capitalismo e, para transformar profundamente as sociedades, insere-se no campo do público e do privado, corroendo até mesmo os fundamentos da democracia liberal. Compreender, portanto, politicamente o neoliberalismo seria compreender a natureza de seu projeto social e político impregnandose nos poderes da Igreja e do Estado.

Neste cenário de correspondência entre política, religião e neoliberalismo, o presente artigo objetiva discutir as temáticas neoliberais que se destacam no jornal Folha

\footnotetext{
5 Estas nuevas subjetividades involucran la percepción de la movilidad social como un resultado del esfuerzo individual y con la manifestación de la gracia de Dios en las proprias obras. La "teología de la prosperidad" postula una afinidade entre una visión neoliberal y la prosperidad económica, ajena al reconocimiento de la acción del Estado y las políticas públicas. Los programas televisivos de estas iglesias hacen referencia al "Pacto con Dios' y el progreso económico que sobreviene del mismo de la mano del emprendedorismo y la iniciativa individual. (GOLDSTEIN, 2020, p. 11-12)
} 


\section{VOZES \\ DIÁLOGO}

Itajaí, V. 20, n.01, jan-jun 2021

de S. Paulo ${ }^{6}$ durante o período eleitoral de 2018, a partir da análise de 69 notícias veiculadas no caderno "Eleições 2018" que interseccionam os três objetos apontados. Propõe-se examinar como o periódico de maior circulação nacional menciona religião e neoliberalismo em notícias pertinentes à eleição corrente. Importante sublinhar que, embora haja uma grande diversidade de fontes de conteúdo no tempo presente, o jornalismo tradicional segue influente na pauta nacional. Conforme indica Michael Schudson (2018, p. 6, tradução nossa) "a maior e mais influente parcela de notícias que circulam sobre assuntos públicos, nacionais e internacionais, vem direta ou indiretamente de organizações de notícias profissionais" "7. Ao atentarmos ao jornalismo voltado à esfera política (HANITZSCH; VOS, 2018), observamos as informações que o jornal considera relevantes compartilhar com o cidadão, indicando e reiterando a força de segmentos religiosos e neoliberais na esfera pública.

A partir de uma prévia categorização, busca-se investigar quais temáticas, atinentes ao discurso neoliberal, se sobressaem nas matérias jornalísticas analisadas, assim como quais religiões e quais presidenciáveis são mais citados nestas mesmas matérias procurando, enfim, refletir sobre como estes elementos se cruzam.

O estudo revela que as temáticas neoliberais que se sobressaem nas matérias analisadas relacionam-se a discursos que envolvem certo grau de mentira ou cinismo, valores ditos familiares e proteção social. No campo religioso, o segmento cristão que se destaca é o evangélico, este principalmente associado aos preceitos que constituem o neossujeito, assim como a prevalência de menções ao candidato Jair Bolsonaro.

\section{Materiais e métodos}

Com a finalidade de identificar as temáticas neoliberais que se apresentaram em notícias que mencionavam alguma religiosidade, durante o período eleitoral de 2018, no jornal Folha de S. Paulo, este artigo prossegue por meio da análise de conteúdo. Esta definida por Laurence Bardin (2011, p. 42) como um agrupamento de técnicas de estudo das comunicações que objetiva coletar "por procedimentos, sistemáticos e objetivos de descrição do conteúdo das mensagens, indicadores (quantitativos ou não) que permitam a inferência de conhecimentos relativos às condições de produção/recepção (variáveis inferidas) destas mensagens”.

\footnotetext{
${ }^{6}$ A escolha desse jornal ocorre em função de ser o periódico com maior circulação no país (MEIO E MENSAGEM, 2020) e por sua influência sobre as demais redações jornalísticas do Brasil (MARQUES et al., 2019).

7 "The largest and most influential share of news items that circulate about public affairs, national and international, comes directly or indirectly from professional news organizations" (SCHUDSON, 2018, p. 6).
} 


\section{VOZES $_{\text {\&IÁLORO }}^{\mid}$}

Itajaí, V. 20, n.01, jan-jun 2021

As notícias foram coletadas por meio da ferramenta de busca no acervo digital da Folha ${ }^{8}$, no período de 16 de agosto de 2018, data do início da campanha eleitoral, a 28 de outubro do mesmo ano, data em que se realizou o segundo turno das eleições. As palavraschave utilizadas foram: religião, religioso, religiosidade, pastor(a), evangélico(a), protestante, católico(a) e padre. Os termos referentes às crenças evangélica e católica foram incluídos na busca por representarem as duas religiões com maior número de adeptos no Brasil, correspondendo a 86\% da população (IBGE, 2012).

Ao todo foram identificados 125 conteúdos que incluíam os termos religiosos mencionados dentro do caderno especial "Eleições 2018". A pesquisa seguiu por meio da busca de elementos neoliberais nestas notícias, sendo encontradas 95 menções neoliberais distribuídas em 69 matérias jornalísticas. A categorização destas referências se deu instigada pela obra A nova razão do mundo: ensaio sobre a sociedade neoliberal, de Pierre Dardot e Christian Laval (2006), nos proporcionando amparo teórico para que pudéssemos propor 13 categorias como temáticas centrais do sistema neoliberal: 1) Cinismo, mentira e brutalidade: verifica-se o menosprezo e a aversão à arte e à cultura, o desleixo da linguagem e dos modos, a ignorância, a arrogância do dinheiro e a brutalidade da dominação; 2) Valores familiares: constata-se a exaltação de um ideal familiar, reiterando ações conservadoras pelo resgate, proteção e manutenção da instituição família; 3) Proteção social: explora-se a vulnerabilidade da sociedade frente à violência, por exemplo, o discurso armamentista passa a ser disseminado; 4) Individualismo: estimula-se certa individualidade, orientando e influenciando a dita 'liberdade de escolha' por meio de recompensas e punições. O indivíduo tão logo terá a 'obrigação de escolher'; 5) Empresa de si mesmo: a valorização do individualismo, consequentemente, coloca o cidadão como empresa de si, o insucesso pode ser considerado patologia, ocasionando o cansaço de si mesmo e a dopagem generalizada; 6) Flexibilizações normativas ao setor privado: questiona-se o enquadramento do setor privado por regulamentações estritas, especialmente em matéria de direito trabalhista e representação dos assalariados; 7) Estado policial: verifica-se a busca por controle da população e desejo de restauração da autoridade das instituições; 8) Privatização de empresas públicas: as estatais sofrem severos ataques, busca-se vilanizar o setor em busca de apoio popular para a consequente privatização; 9) Autocoerção e autoculpabilização: considera-se que a sociedade neoliberal vincula o modelo de governo à maneira como o próprio indivíduo se governa de modo que o neoliberalismo se impregna em todas as relações, integrando vida pessoal e profissional; 10) Desempenho e consumo: a perversão logo integrará a forma de vida do sujeito neoliberal, tratando do consumo de parceiros como objetos, descartados logo que considerados insuficientes. O neossujeito oscilará entre a depressão e a perversão, condenado ao duplo. Nesta coerência, o neoliberalismo saberá "manter uma 'ordem pública' quando é preciso incitar os indivíduos

8 Disponível em: www.acervo.folha.com.br 


\section{VOZES \\ DIÁLOGO}

Itajaí, V. 20, n.01, jan-jun 2021

ao gozo, evitando ao mesmo tempo a explosão desmedida" (DARDOT; LAVAL, 2016, p. 376); 11) Concorrência: ao passo que os indivíduos são estimulados a conviver num regime de concorrência, "a polarização entre os que desistem e os que são bem-sucedidos mina a solidariedade e a cidadania" (DARDOT; LAVAL, 2016, p. 09); 12) Negação do sistema tributário progressivo: há um posicionamento contrário a aplicação do imposto progressivo, buscando preservar que o contribuinte com maior renda não pague mais tributos; e 13) Produtividade: a mão de obra é explorada à exaustão, baixa-se o custo do trabalho e aumenta-se a carga produtiva.

Note-se que mais de uma temática neoliberal pode se apresentar na mesma matéria, logo, a presença de uma não anula outra. Por isso, os números de menções ultrapassam o total de notícias.

A partir da classificação destes conteúdos, realiza-se o cruzamento simples das variáveis para identificar as temáticas neoliberais que se destacam, assim como a associação delas às religiões e candidatos presidenciáveis mencionados. Por fim, efetua-se uma análise que reflete sobre os resultados desta tríade: religião, política e neoliberalismo.

\section{Resultados e discussões}

Os resultados encontrados no caderno "Eleições 2018", do Jornal Folha de São Paulo, revelam que 125 notícias mencionaram algum termo religioso. Entre estas, 69 (55\%) comunicavam alguma temática neoliberal, as quais tiveram destaque expressivo as categorias: "Cinismo, mentira e brutalidade", "Valores familiares" e "Proteção social", a primeira presente em $55 \%$ destas notícias, a segunda em $54 \%$ e a terceira em $22 \%$ (Tabela $1)$.

Tabela 1 - Temáticas neoliberais

\begin{tabular}{|l|c|c|}
\hline \multicolumn{1}{|c|}{ Temáticas neoliberais } & $\#$ & $\%$ \\
\hline Cinismo, mentira e brutalidade & 38 & $55 \%$ \\
\hline Valores familiares & 37 & $54 \%$ \\
\hline Proteção social & 15 & $22 \%$ \\
\hline Individualismo & 3 & $4 \%$ \\
\hline Empresa de si mesmo & 1 & $1 \%$ \\
\hline Flexibilizações normativas ao setor privado & 1 & $1 \%$ \\
\hline Estado policial & 0 & $0 \%$ \\
\hline Privatização de empresas públicas & 0 & $0 \%$ \\
\hline Autocoerção e autoculpabilização & 0 & $0 \%$ \\
\hline Desempenho e consumo & 0 & $0 \%$ \\
\hline Concorrência & 0 & $0 \%$ \\
\hline Negação do sistema tributário progressivo & 0 & $0 \%$ \\
\hline Produtividade & 0 & $0 \%$ \\
\hline
\end{tabular}




\section{VOZES

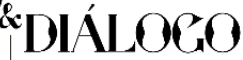

Itajaí, V. 20, n.01, jan-jun 2021

Fonte: Autores, 2020.

Nesta intersecção entre religião e política, observa-se a ausência de temáticas que, em certa medida, viriam comunicar-se com pautas econômicas. Categorias que poderiam aproximar-se de setores empresariais e financeiros são deixadas de lado, para potencializar, sim, pautas de caráter moral, valorizando a família e elegendo potenciais inimigos na construção de imaginários referente à insegurança e suposta imoralidade. Em diversos momentos, identificam-se falas de candidatos com informações errôneas e até mesmo mentirosas, como as ditas fake news que expunham o chamado "kit gay"9 e as teorias conspiracionistas sobre fraude nas urnas. Ao focarmos na categoria "valores familiares" encontramos a frase "defesa da família” em 13 conteúdos, seguidas de costumes morais, sinalizando que diversas vezes um misto desses valores se pronuncia no mesmo conteúdo. A crítica ao aborto e aos direitos de grupos LGBTQIA+ também são mencionadas nesta categoria. Já no campo da proteção social, grupo com menor número de menções entre as três categorias, vemos que a alusão ao armamento da população foi o tópico mais citado, seguido pelo discurso generalista de ampliar a segurança.

No que tange a menção neoliberal, tendo em consideração religiões específicas (Figura 1), constata-se que os evangélicos representam maioria, aludidos em $68 \%$ das notícias analisadas. O segundo grupo em destaque é o de católicos, referenciado em 29\% dos conteúdos, seguidos por crença indeterminada, com 16\% de citações. Dados que reforçam a relevância protestante no quadro político, pois ostentam ampla margem em relação às demais citações religiosas. Pertinente indicar que o grupo evangélico expressa clara proximidade às pautas neoliberais, famosas por serem "conservadoras nos costumes e liberais na economia”. No espectro conservador temos como exemplo a animosidade da Pastora Damares Alves, ministra da Mulher, Família e Direitos Humanos, em relação ao aborto e a chamada "ideologia de gênero" ${ }^{10}$, enquanto no campo econômico destacamos o apoio do deputado Silas Câmara, atual coordenador da Frente Parlamentar Evangélica,

${ }^{9} \mathrm{O}$ dito "kit gay", acusado de visar a difusão de pornografia às crianças, era na verdade um projeto que se chamava Escola sem Homofobia, cujo objetivo era "combater a homofobia nas escolas brasileiras, visto que a orientação sexual é um dos grandes motivadores do bullying escolar. Composto por um caderno, boletins, audiovisuais, cartaz e carta de apresentação para os/as gestores/as em educação, este kit anti-homofobia era parte do Projeto Escola sem Homofobia, proposto pelo Ministério da Educação, à época encabeçado por Fernando Haddad e por ONGs nacionais e internacionais e avalizado pela UNESCO" (MARANHÃO FILHO; COELHO; DIAS, 2019, p. 69).

${ }^{10}$ De matriz católica, mas amplamente aceito e propagado por diversos grupos evangélicos conservadores, a ideologia de gênero é, segundo Rogério Junqueira (2018, p. 451), um "artefato retórico e persuasivo" por meio do qual busca-se realizar intervenções na arena pública em defesa da "família tradicional". "Essa cruzada implica intensa mobilização política e discursiva em favor da reafirmação das hierarquias sexuais, de uma assim dita 'primazia dos pais na formação moral e sexual dos filhos', da retirada da educação para a sexualidade nas escolas, da restrição ao acesso de adolescentes a informações sobre saúde sexual, do rechaço a arranjos familiares não heteronormativos, da repatologização das homossexualidades e transgeneridades, entre outros posicionamentos que representam cerceamentos a direitos e garantias fundamentais". 


\section{VOZES $_{\text {\&IÁLORO }}^{\mid}$}

Itajaí, V. 20, n.01, jan-jun 2021

a favor da reforma trabalhista ${ }^{11}$ proposta pelo então presidente Michel Temer, em abril de 2017 (GOLDSTEIN, 2020).

Figura 1 - Gráfico sobre menções neoliberais em comparação às religiões

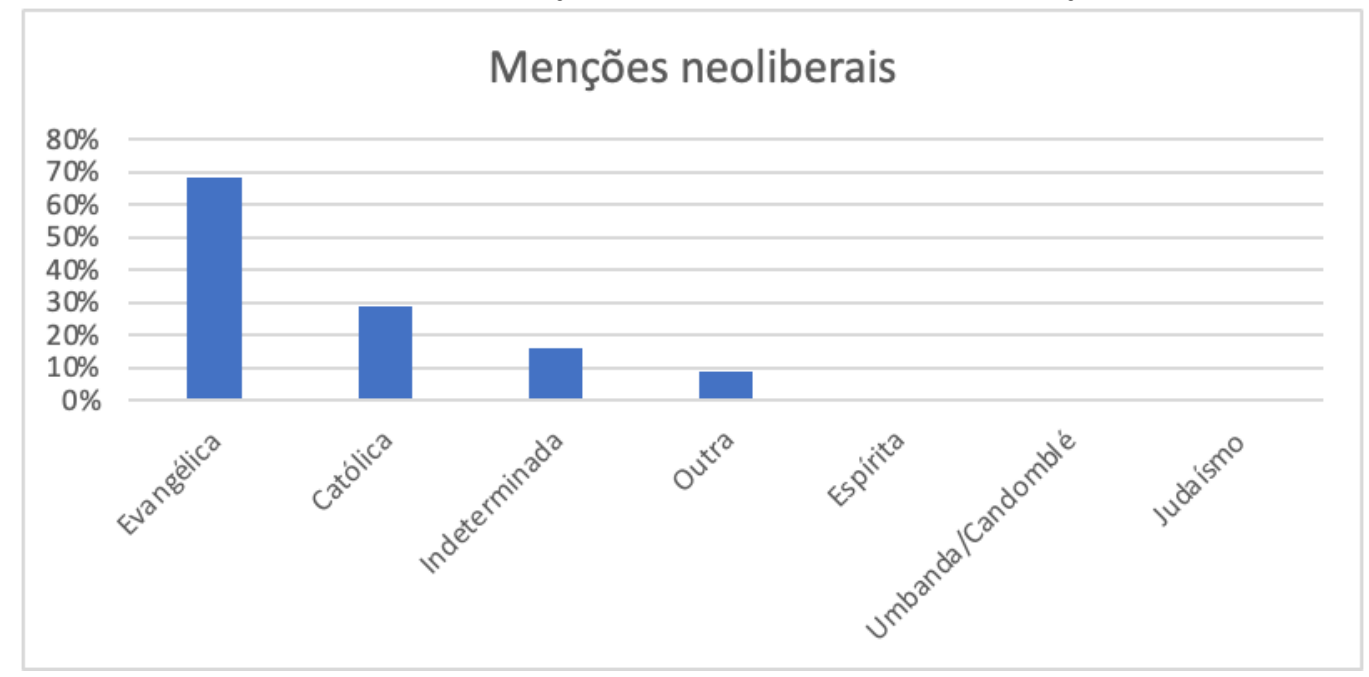

Fonte: Autores, 2020.

Ronaldo de Almeida (2019, p. 43) aponta que o fato de os evangélicos se sobressaírem entre as classes populares e médias da sociedade, seu liberalismo econômico "não dispensa as exigências de serviços públicos (saúde, educação, segurança, saneamento etc.) e a seguridade social (aposentadoria e regras trabalhistas)”. Deste modo, a redução do Estado é defendida por meio de discursos anticorrupção e contra privilégios do setor público, visto que a agenda neoliberal, especialmente a econômica, tem baixa adesão popular. "Não por acaso ocorrem alianças estratégicas entre ultraliberais associados à pauta de segurança e dos costumes como forma de melhorar o desempenho eleitoral" (ALMEIDA, 2019, p. 43), fato este que presenciamos nos dados apresentados. As agendas econômicas são minimizadas, enquanto as de cunho moral e de segurança se sobressaem amplamente, enfatiza-se as pautas mais atraentes à população, estas que também podem atuar como uma distração em momentos de decisões econômicas.

Verifica-se que a Igreja Católica, protagonista por séculos na história política do Brasil, apresenta-se como coadjuvante nesta análise. Consequência talvez de ter um Papa que rejeita abertamente o neoliberalismo ${ }^{12}$ ou pelo sucesso crescente dos evangélicos na política. Outro aspecto interessante a ser pontuado neste gráfico é que as denominações

11 "Em vigor desde 2017, a reforma trabalhista (Lei 13.467, de 2017) mudou as regras relativas à remuneração, plano de carreira e jornada de trabalho, entre outras. A norma foi aprovada para flexibilizar o mercado de trabalho e simplificar as relações entre trabalhadores e empregadores" (AGÊNCIA SENADO, 2019).

12 Disponível em: https://brasil.elpais.com/sociedade/2020-10-04/papa-francisco-criticaneoliberalismo-e-populismo-em-seu-documento-mais-politico.html 


\section{VOZES $_{\text {\&IÁLORO }}^{\mid}$}

Itajaí, V. 20, n.01, jan-jun 2021

religiosas espírita, judaica, umbanda e candomblé não se apresentam em nenhuma notícia, dado que corrobora a proeminência cristã tradicional (antes católica, agora evangélica) no enlace à política nacional.

Ao focalizarmos o olhar para quais temáticas foram mais citadas em comparação às religiões (Figura 2), vemos como as categorias "Cinismo, mentira, brutalidade", "Valores familiares" e "Proteção social" se destacam em todas as religiosidades. Contudo, enquanto os evangélicos revelam uma proeminência nos dois primeiros temas, as demais religiões se relacionam às três categorias numa proporção mais similar e distribuída.

Figura 2 - Gráfico sobre temáticas neoliberais em comparação às religiões

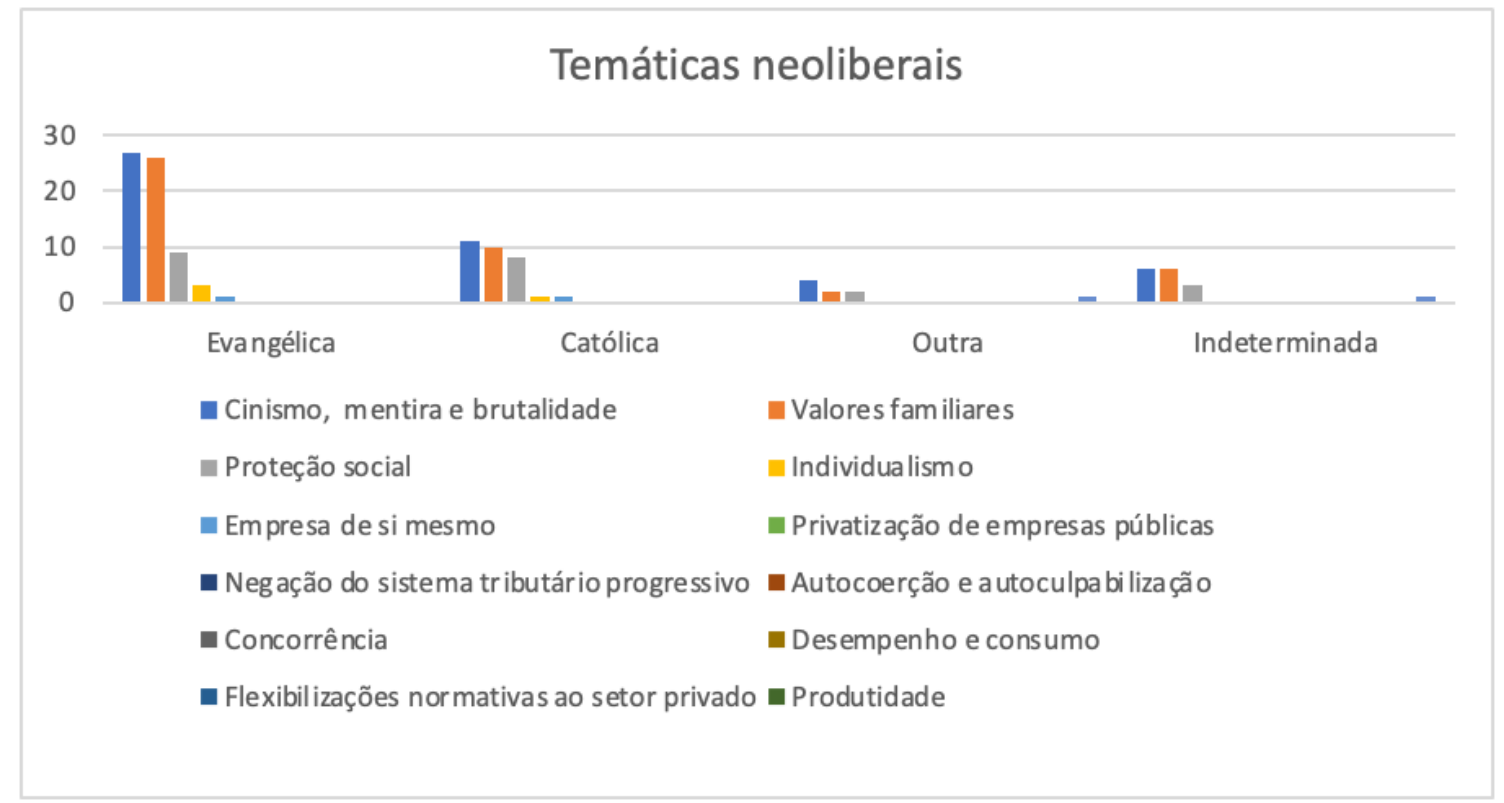

Fonte: Autores, 2020.

Logo, podemos ir ao encontro de Dardot e Laval, compreendendo como que o neoliberalismo ultrapassa uma ideologia e política econômica, abarcando um projeto social e político. Acomodando-se em discursos morais e religiosos viria ocorrer o que os autores chamam de subjetivação neoliberal, ou seja, “com o neoliberalismo o que está em jogo é nada mais nada menos que a forma de nossa existência, isto é, a forma como somos levados a nos comportar, a nos relacionar com os outros e com nós mesmos" (DARDOT; LAVAL, 2016, p. 16). A racionalidade política seria a racionalidade governamental, em que governar é “conduzir a conduta” dos indivíduos, em domínios distintos, na escola, na fábrica e, como verificamos, na igreja. Nas sociedades neoliberais a forma que o governo encontra para disciplinar é por meio do autogoverno, em que o próprio indivíduo exerce técnicas de conduta para si e para outro. O indivíduo pode agir ativamente, conformando-se por si mesmo a certas normas, acreditando ter a liberdade para tais execuções normativas, assim tornando possível "esvaziar a democracia de sua substância sem a extinguir formalmente 


\section{VOZES $_{\text {\&IÁLORO }}^{\mid}$}

Itajaí, V. 20, n.01, jan-jun 2021

(DARDOT; LAVAL, 2016, p. 20). Trata-se de uma "'racionalização da existência' que, afinal, como dizia Margaret Thatcher, pode "mudar a alma e o coração" (DARDOT; LAVAL, 2016, p. 27).

Podemos dizer que o neoliberalismo emprega técnicas de poder sobre as condutas e as subjetividades, não se reduzindo a uma esfera mercantil de acumulação de capital, pois o sistema econômico é também um sistema antropológico de produção. O neoliberalismo estaria definindo além de um regime de acumulação, uma outra sociedade - por isso, a importância de falarmos de uma sociedade neoliberal e não somente política ou economia neoliberais.

Logo, esta subjetivação neoliberal irá determinar as campanhas eleitorais e as formas de dar a ver os candidatos em disputa. Vejamos que em relação a menção aos candidatos à presidência da República (Figura 3), todos foram encontrados em pelo menos uma notícia. Todavia, a análise evidencia que Jair Bolsonaro (PSL - Partido Social Liberal) foi quem se sobressaiu, o candidato desponta em $84 \%$ dos conteúdos analisados, seguido por Haddad com 49\% de menções. Geraldo Alckmin, Ciro Gomes e Marina Silva apresentam 20\%, 16\% e 10\% de citações respectivamente. Todos os demais presidenciáveis tiveram uma presença inferior a 10\%. A proeminência de Bolsonaro nestes conteúdos pode ser associada ao recorrente discurso moralista "em defesa da família" e o uso do slogan "Deus acima de todos", elementos que se relacionam à categoria "valores familiares". Soma-se ainda questionamentos sobre a validade da urna eletrônica e a defesa pelo armamento da população, características que o associam às categorias "cinismo, mentira, brutalidade" e "proteção social".

Figura 3 - Gráfico sobre menções neoliberais em relação aos presidenciáveis

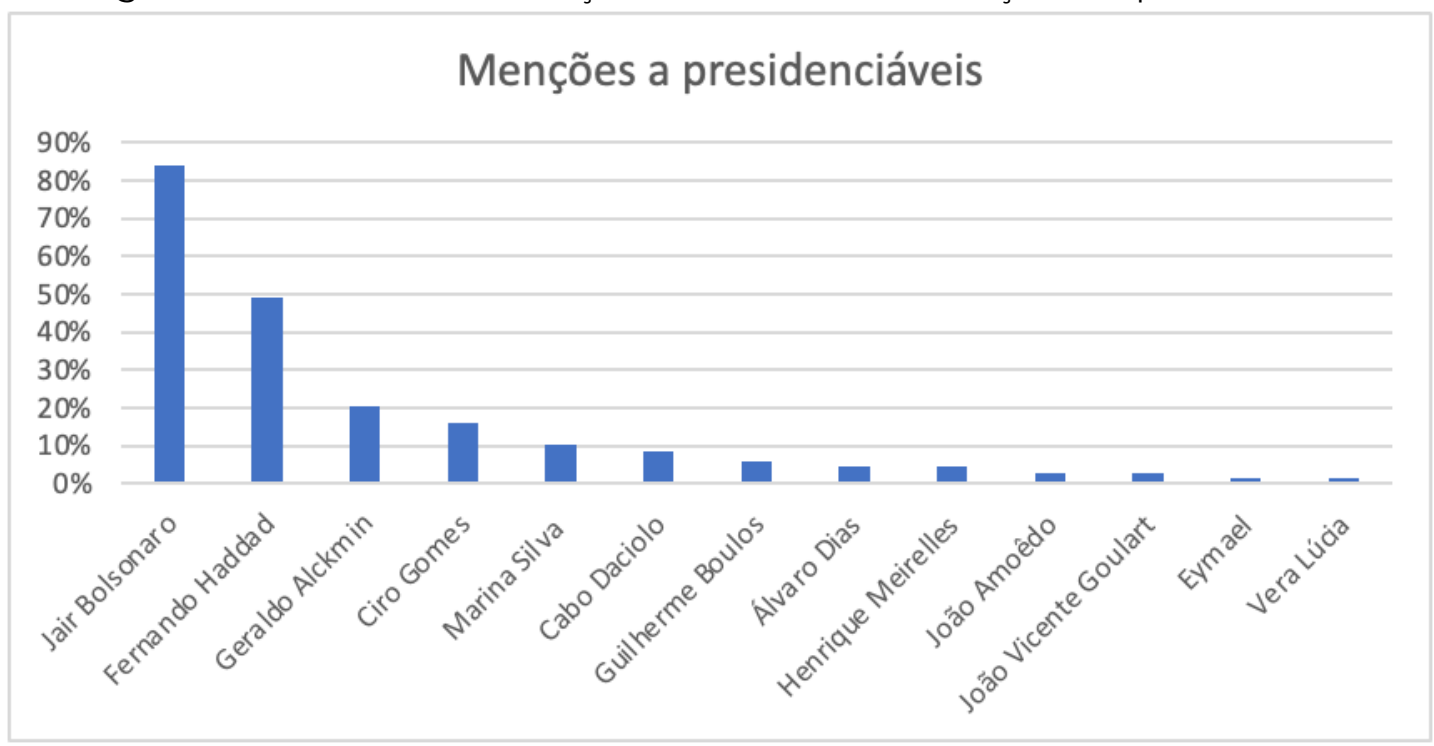

Fonte: Autores, 2020. 


\section{VOZES $_{\text {\&DÁLORO }}^{\mid}$}

Itajaí, V. 20, n.01, jan-jun 2021

É possível verificarmos, portanto, que a sociedade neoliberal vincula o modelo de governo à maneira como o próprio indivíduo racionaliza uma forma de existência de modo que o neoliberalismo se impregna em todas as relações, como observamos na presente análise, numa linha tênue e oblíqua, delineando crenças religiosas, aqui a evangélica, e discursos políticos, nesta ocasião associados a Jair Bolsonaro. Ou seja, o discurso neoliberal impregna-se em variados âmbitos da vida, justapondo discursos políticos e crenças religiosas, com o predomínio evangélico, num Estado supostamente laico.

\section{Considerações finais}

Refletir sobre o relacionamento entre religião e neoliberalismo, a partir do caderno político do jornal Folha de S. Paulo, é verificar de que forma estes elementos se cruzam durante o processo eleitoral e quais vertentes neoliberais são privilegiadas pelo jornalismo tradicional nesta intersecção. No quesito temáticas, observa-se como as relacionadas à moral e segurança, assim como o cinismo e a mentira, formam o grupo de destaque no recorte analisado.

Ao focalizarmos nas religiosidades e candidatos à presidência, o destaque foi para os evangélicos e Jair Bolsonaro, grupo que permaneceu alinhado durante todo o processo eleitoral. Esse segmento cristão, conforme o resultado desta eleição mostrou, votou em massa no então candidato do PSL, cristalizando uma aliança de visão comum (GOLDSTEIN, 2020). Por sua vez, os católicos, grupo que se apresentou mais polarizado na escolha pelo novo presidente, apareceram com menos força que os evangélicos. Notese que as demais religiosidades não se destacaram nestes conteúdos, fato que sustenta o cristianismo tradicional (antes católico, agora evangélico) como o sujeito que ascende à visibilidade da comunicação e política.

A relevância evangélica neste pleito nos remete ao projeto de neocristandade lançado em 1986 por um líder da Igreja Assembleia de Deus, o qual "declarou que 'somente os eleitos de Deus devem ocupar os postos-chave da nação'. Para atingir seus objetivos, as principais igrejas, sobretudo a AD, a IEQ e a IURD, seguiram um modelo corporativo, apontando seus candidatos oficiais" (SIEPIERSKI, 1997, p. 53-54), o que não os classifica rigorosamente como religiosos, mas sim aprovados por tais. Aparentemente este plano tem prosperado, a exemplo dos resultados descritos neste artigo.

A proeminência de Bolsonaro nos conteúdos analisados pode ser compreendida pelo seu alinhamento ao discurso que apoia o armamento da população, difusão de notícias comprovadamente falsas e a preservação de valores ditos tradicionais, difundidos por candidatos evangélicos ao longo das últimas décadas (ALVES; CASSOTTA, 2020; MARIANO, 2011). O então candidato do PSL os reforça por meio de falas "em defesa da família" e o uso do slogan "Deus acima de todos". Além disso, outro ponto relevante foi o apoio recebido de lideranças evangélicas de destaque midiático (SANTOS; VAZ; PRADO 


\section{VOZES $_{\text {\&IÁLOGO }}^{\mid}$}

Itajaí, V. 20, n.01, jan-jun 2021

JUNIOR, 2020). Note-se que apesar do realce às pautas mencionadas, Bolsonaro indicou Paulo Guedes como seu escolhido para o ministério da economia, esta preferência por "um ministro ultraliberal no início da campanha não foi só para suprir o desconhecimento econômico do candidato; ela também sinaliza um jogo econômico maior” (ALMEIDA, 2019, p. 41). Logo, a pauta econômica neoliberal está segura com seu ministro e ele pode se associar às pautas neoliberais de apelo popular em consonância aos padrinhos religiosos.

Observar como um influente meio de comunicação apresenta as menções neoliberais e religiosas no caderno eleitoral, a partir de uma compreensão social da construção das notícias, na qual elas se apresentam como um campo dinâmico, moldado por aspectos sociais (PAUL; BERKOWITZ, 2019), indica como o objeto estudado se delineia em consonância aos destaques do tempo presente. Aqui o jornalismo indica e reafirma quem são os protagonistas na intersecção religião e política, assim como estabelece de que maneira estes sujeitos se associam às pautas neoliberais.

Compreendemos, portanto, que o neoliberalismo se apresenta como um sistema aceito e seguido por instituições políticas e religiosas, ganhando destaque na mídia como um processo comunicacional (e social), pois os poderes oblíquos afetam, como vimos, processos eleitorais, assim como a constituição de políticas públicas e seus efeitos no cotidiano do sujeito, este neossujeito atravessado de valores morais que acabam por se contabilizar em votos. Ademais, os jornais atuam como tecnologias do imaginário (SILVA, 2012), funcionando como materializadoras de repertórios, crenças, aspirações e pulsões de um grupo social que, no Brasil no ano eleitoral de 2018, veio à tona cristalizando todo o conservadorismo ora submerso em décadas anteriores. Nesse sentido, a religião (em especial o segmento evangélico do cristianismo) se apresenta como “infantaria” do neoliberalismo, já que esta (sob o comando ideológico neoliberal) trava diariamente uma guerra simbólica de mentes e corações entre o bem (entendido aqui como o mercado neutro, impoluto, incorruptível) e o mal (compreendido como o Estado - parcial, corrupto, opressor); e onde seus arquitetos intelectuais jamais põem seus pés, mas, ao contrário (e assim como Pilatos), estão sempre de mãos lavadas.

\section{Referências}

AGÊECIA SENADO. Aprovada em 2017, reforma trabalhista alterou regras para flexibilizar o mercado de trabalho. 2019. Disponível em: <https://www12.senado.leg.br/noticias/materias/2019/05/02/aprovada-em-2017reforma-trabalhista-alterou-regras-para-flexibilizar-o-mercado-de-trabalho $>$. Acesso em: 05 nov. 2020.

ALENCAR, G. F. de. Jair Messias Bolsonaro: o " eleito” de Deus? Revista Brasileira de História das Religiões, n. 37, p. 161-175, 2020. 


\section{VOZES $_{\& \text { DIÁLORO }}^{\mid}$}

Itajaí, V. 20, n.01, jan-jun 2021

ALMEIDA, R. de. Deus acima de todos. In: Democracia em risco? 22 ensaios sobre o Brasil hoje. 1. ed. São Paulo: Companhia das Letras, 2019.

ALVES, M.; CASSOTTA, P. L. Políticos de Deus: análise das campanhas de evangélicos eleitos para Deputado Federal por São Paulo (2010, 2014 e 2018). Revista Debates, v. 14, p. 36-59, 2020.

BARDIN, L. Análise de conteúdo. 1. ed. [s.l.] Edições 70, 2011.

DARDOT, Pierre; LAVAL, Christian. A nova razão do mundo: ensaio sobre a sociedade neoliberal. São Paulo: Boitempo, 2016.

FILHO FIGUEREDO, V. Entre o palanque e o púlpito: mídia, religião e política. [s.l.] Annablume, 2005.

GOLDSTEIN, A. A. Poder evangélico: Cómo los grupos religiosos están copando la política en América. 1. ed. Ciudad Autónoma de Buenos Aires: Marea, 2020.

HANITZSCH, T.; VOS, T. P. Journalism beyond democracy: A new look into journalistic roles in political and everyday life. Journalism, v. 19, n. 2, p. 146-164, 2018.

IBGE. Censo 2010: número de católicos cai e aumenta o de evangélicos, espíritas e sem religião. Disponível em: https://censo2010.ibge.gov.br/noticiascenso?id=3\&idnoticia=2170\&view=noticia. Acesso em: 13 jul. 2020.

JUNQUEIRA, R. D. A invenção da "ideologia de gênero": a emergência de um cenário político - discursivo e a elaboração de uma retórica reacionária antigênero. Psicologia Política, v. 18, n. 43, p. 449-502, 2018.

MARANHÃO FILHO, E. M. DE A.; COELHO, F. M. F.; DIAS, T. B. "Fake news acima de tudo, fake news acima de todos": Bolsonaro e o "kit gay", "ideologia de gênero" e fim da "família tradicional”. Correlatio, v. 17, n. 2, p. 65, 2019.

MARIANO, R. Crescimento Pentecostal no Brasil: fatores internos. Revista de Estudos da Religião, p. 68-95, 2008.

MARIANO, R. Neopentecostais: sociologia do novo pentecostalismo no Brasil. 5. ed. São Paulo: Edições Loyola, 2014. 


\section{VOZES $_{\& \text { DIÁLORO }}^{\mid}$}

Itajaí, V. 20, n.01, jan-jun 2027

MARQUES, F. P. J. et al. SIMILAR, BUT NOT THE SAME: Comparing Editorial and News Agendas in Brazilian Newspapers. Journalism Practice, v. 14, n. 9, p. 1-21, 2019.

MEIO E MENSAGEM. Circulação dos maiores jornais do País cresce em 2019. Disponível em: https:/www.meioemensagem.com.br/home/midia/2020/01/21/circulacaodos-maiores-jornais-do-pais-cresce-em-2019.html. Acesso em: 24 out. 2020.

PAUL, S.; BERKOWITZ, D. Social Construction of News. The International Encyclopedia of Journalism Studies, p. 1-6, 2019.

RODRIGUES-SILVEIRA, R.; CERVI, E. U. Evangélicos e voto legislativo: Diversidade confessional e voto em deputados da bancada evangélica no Brasil. Latin American Research Review, v. 54, n. 3, p. 560-573, 2019.

SANTOS, M. B.; VAZ, A.; PRADO JUNIOR, T. Mídia, religião e política: o discurso combativo de pastores pentecostais nas eleições presidenciais de 2018. Tríade: comunicação, cultura e mídia, v. 8, p. 150-172, 2020.

SIEPIERSKI, P. D. Pós-Pentecostalismo e Política no Brasil. Estudos Teológicos, v. 37, p. p.47-61, 1997.

SILVA, J.M. As tecnologias do imaginário. Porto Alegre: Sulina, 2012.

SCHUDSON, M. News. The International Encyclopedia of Journalism Studies, p. $1-7,2018$. 